\title{
Palstimolide A: A Complex Polyhydroxy Macrolide with Antiparasitic Activity
}

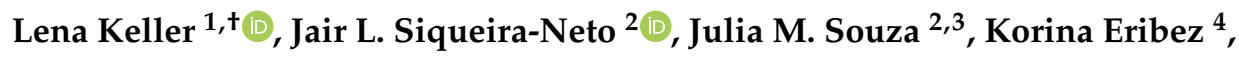 \\ Gregory M. LaMonte ${ }^{3}$, Jennifer E. Smith ${ }^{5}$ and William H. Gerwick ${ }^{1,2, * \mathbb{C}}$
}

1 Center for Marine Biotechnology and Biomedicine, Scripps Institution of Oceanography, University of California San Diego, La Jolla, CA 92037, USA; Lena.Keller@helmholtz-hips.de

2 Skaggs School of Pharmacy and Pharmaceutical Sciences, University of California San Diego, La Jolla, CA 92093, USA; jairlage@ucsd.edu (J.L.S.-N.); jmsouza@ucsd.edu (J.M.S.)

3 Núcleo de Pesquisas em Ciências Exatas e Tecnológicas, Universidade de Franca, Franca, SP 14404-600, Brazil; greg.lamonte@gmail.com

4 Department of Pediatrics, School of Medicine, University of California San Diego, La Jolla, CA, 92093, USA; korina.hernandez@yahoo.com

5 Marine Biology Division, Scripps Institution of Oceanography, University of California San Diego, La Jolla, CA 92037, USA; jes013@ucsd.edu

* Correspondence: wgerwick@ucsd.edu; Tel.: +1-858-534-0576

+ Present Address: Department of Microbial Natural Products, Helmholtz Institute for Pharmaceutical Research Saarland (HIPS), Helmholtz Center for Infection Research, Campus E8.1, 66123 Saarbruecken, Germany.

Received: 4 March 2020; Accepted: 29 March 2020; Published: 31 March 2020

\begin{abstract}
Marine Cyanobacteria (blue-green algae) have been shown to possess an enormous potential to produce structurally diverse natural products that exhibit a broad spectrum of potent biological activities, including cytotoxic, antifungal, antiparasitic, antiviral, and antibacterial activities. Here, we report the isolation and structure determination of palstimolide $\mathrm{A}$, a complex polyhydroxy macrolide with a 40-membered ring that was isolated from a tropical marine cyanobacterium collected at Palmyra Atoll. NMR-guided fractionation in combination with $\mathrm{MS}^{2}$-based molecular networking and isolation via HPLC yielded $0.7 \mathrm{mg}$ of the pure compound. The small quantity isolated along with the presence of significant signal degeneracy in both the ${ }^{1} \mathrm{H}$ and ${ }^{13} \mathrm{C}-\mathrm{NMR}$ spectra complicated the structure elucidation of palstimolide A. Various NMR experiments and solvent systems were employed, including the LR-HSQMBC experiment that allows the detection of long-range ${ }^{1} \mathrm{H}-{ }^{13} \mathrm{C}$ correlation data across 4-, 5-, and even 6-bonds. This expanded NMR data set enabled the elucidation of the palstimolide's planar structure, which is characterized by several 1,5-disposed hydroxy groups as well as a tert-butyl group. The compound showed potent antimalarial activity with an $\mathrm{IC}_{50}$ of $223 \mathrm{nM}$ as well as interesting anti-leishmanial activity with an $\mathrm{IC}_{50}$ of $4.67 \mu \mathrm{M}$.
\end{abstract}

Keywords: natural products; cyanobacteria; antimalarial agents; malaria; leishmaniosis; macrolide

\section{Introduction}

Marine cyanobacteria are extraordinarily rich in biologically active and structurally diverse natural products (NPs), often times deriving from hybrid nonribosomal peptide synthetase (NRPS) and polyketide synthase (PKS) biosynthetic pathways [1-3]. However, those cyanobacterial NPs with an exclusive PKS origin are often cyclized to form macrolides, a class of compounds that generally possesses important biomedical properties [4,5]. From other microbial sources, macrolide NPs have proven utility in treating human diseases, such as erythromycin and clarithromycin, as antibiotics, tacrolimus as a macrolide immunosuppressant, and amphotericin B and nystatin as antifungals. Cyanobacteria 
are also known to produce a variety of structurally diverse macrolides that possess biological activities with potential applications in medicine. These carbon-chain compounds show a high diversity in their skeleton architectures along with complex spatial configurations. Examples of macrolides from Cyanobacteria include bastimolide A and B [6,7], amantelides A and B [8], nuiapolide [9], caylobolide A and B [10,11], swinholide A [12], phormidolide [13], cyanolide A [14], and palmyrolide [15].

Here, we report the newest member of the macrolide class from the marine cyanobacterium Leptolyngbya sp., given the trivial name palstimolide A (1), a name which reflects its collection from Palmyra Atoll in the Central Pacific and structural relationship to the bastimolides [6,7]. As distinctive structural features, palstimolide A embraces seven 1,5-diol equivalents and one 1,7 diol around a 40-membered macrolide ring, along with a $t$-butyl group at its distal terminus. In vitro, palstimolide A displays potent antimalarial and modest anti-leishmanial activity.

\section{Results and Discussion}

\subsection{Isolation and Structure Elucidation}

Cyanobacterial colonies of the genus Leptolyngbya sp. were collected at Palmyra Atoll by shallow water snorkeling. The crude extract was initially fractionated using vacuum liquid chromatography (VLC) as well as solid phase extraction (SPE) for further analysis by MS and NMR. Our discovery strategy to locate natural products with novel structural frameworks included $\mathrm{MS}^{2}$-based metabolomics (Molecular Networking) [16] for strain selection and dereplication as well as NMR-guided fractionation for isolation driven by structural features. This approach indicated the presence of an unusual macrolide in the extract of a cyanobacterial field collection from the Palmyra Atoll; HPLC isolation ultimately yielded $0.7 \mathrm{mg}$ of the pure compound. The small quantity isolated along with significant overlap in both the proton and carbon spectra made the NMR-based structure elucidation of $\mathbf{1}$ quite challenging.

Various NMR experiments and solvent systems were employed to solve the structure of $\mathbf{1}$, including the LR-HSQMBC that allows the detection of 4-, 5-, and even 6-bond long-range ${ }^{\mathrm{n}} \mathrm{J}_{\mathrm{CH}}$ heteronuclear couplings [17] as well as 1D TOCSY with different mixing times. Using this expanded NMR data set, palstimolide A (1) was characterized as possessing seven contiguous 1,5-diols (or diol equivalents) and a tert-butyl substituent (Figure 1), and belonging to a small group of cyanobacterial polyhydroxy macrolides that includes bastimolide A (2) and B [6,7], nuiapolide (3) [9], and amantelides A (4) and B (5) [8]. All of these macrolides share a 40-membered ring with several hydroxy groups, a tert-butyl moiety, and an $\alpha, \beta$-unsaturated carboxyl group (Figure 1). Interestingly, all members of this structural class differ in the arrangement and number of the hydroxy groups with palstimolide $\mathrm{A}$ being the only member that contains only 1,5- and 1,7-diols but no 1,3-diol relationships.
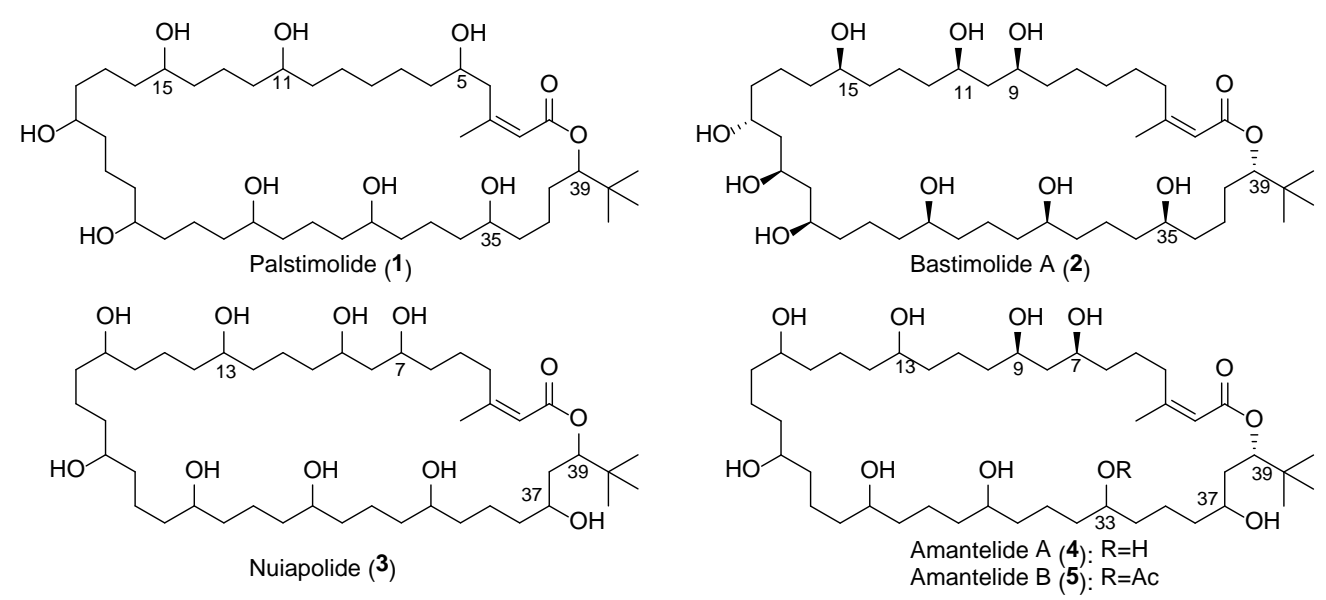

Figure 1. Structure of palstimolide A (1) together with the related cyanobacterial 40-membered polyhydroxy macrolides bastimolide A [6], amantelides A and B [8], and nuiapolide [9]. 
HRESIMS of palstimolide A (1) displayed an ion peak at $m / z 773.6182$ (calcd for $\mathrm{C}_{44} \mathrm{H}_{85} \mathrm{O}_{10}{ }^{+}$, 773.6137), consistent with the molecular formula $\mathrm{C}_{44} \mathrm{H}_{84} \mathrm{O}_{10}$ that inherently contains three double-bond equivalents (DBE). The ${ }^{1} \mathrm{H}-\mathrm{NMR}$ spectrum of $\mathbf{1}$ in pyridine- $d_{5}$ (Figure S1, Supplementary Materials) exhibited highly overlapping signals characteristic of a polyhydroxy macrolide, including broad signals indicative of eight hydroxy groups at $\delta 5.82(1 \mathrm{H}), 5.74(6 \mathrm{H})$, and $5.66(1 \mathrm{H})$ along with oxymethine signals at $4.21(1 \mathrm{H}$, broad), 3.93-4.00 (5H, overlap), and 3.87 ( $2 \mathrm{H}$, overlap). Another downfield shifted oxymethine signal at $\delta 5.08(1 \mathrm{H}, \mathrm{dd}, J=10.3,1.7 \mathrm{~Hz})$ indicated an ester bond and a downfield singlet at $\delta 6.01(1 \mathrm{H}, \mathrm{s})$ indicated the presence of a conjugated double bond. The proton NMR spectrum also showed several overlapping methylene signals between 1.4 and $1.9 \mathrm{ppm}$, an olefinic methyl signal at $\delta 2.09(3 \mathrm{H}, \mathrm{s})$ as well as a large singlet at $\delta 0.94(9 \mathrm{H}, \mathrm{s})$ indicative of a tert-butyl group. The HSQC spectrum revealed the presence of a downfield shifted methylene group $\left(\delta_{\mathrm{C}-4} 42.0, \delta_{\mathrm{H}-4}\right.$ $3.38 / 2.92)$ in addition to six methylene groups $\left(\delta_{\mathrm{C}-7} 23.5, \delta_{\mathrm{H}-7} 1.80 / 1.58, \delta_{\mathrm{C}-8} 30.4, \delta_{\mathrm{H}-8} 1.48 / 1.42, \delta_{\mathrm{C}-9}\right.$ $\left.26.5, \delta_{\mathrm{H}-9} 1.74 / 1.58, \delta_{\mathrm{C}-10} 38.4, \delta_{\mathrm{H}-10} 1.69, \delta_{\mathrm{C}-37} 23.5, \delta_{\mathrm{H}-37} 1.92 / 1.60, \delta_{\mathrm{C}-39} 30.2, \delta_{\mathrm{H}-39} 1.70 / 1.64\right)$ and two highly-crowded methylene areas $\left(\delta_{\mathrm{C}} 38.7-38.2, \delta_{\mathrm{H}} 1.82-1.75, \delta_{\mathrm{C}} 22.8-22.4, \delta_{\mathrm{H}} 2.15-2.04 / 1.89-1.76\right)$.

In-depth analysis of the standard 2D-NMR data together with more specific NMR experiments, such as the LR-HSQMBC [17] and utilization of different solvent systems, allowed elucidation of the planar structure of palstimolide A (1). A sequential spin system starting from the methylene protons at $\delta 3.38 / 2.92(\mathrm{H}-4)$ and followed by an oxymethine proton at $\delta 4.21(\mathrm{H}-5)$, methylene protons at $\delta 1.78$ (H-6), and two methylene protons at $\delta 1.80 / 1.58$ (H-7), were deduced from TOCSY and COSY spectra. Together with HMBC signals, the spin system was extended with three more methylene groups to another oxymethine proton at $\delta 3.87(\mathrm{H}-11)$, allowing the assignment of the 1,7-diol unit. HMBC correlations from the methine proton at $\delta 6.01$ (H-2) to a carbonyl carbon at $\delta 167.1$ (C-1), a quarternary carbon at $\delta 159.9$ (C-3), the methylene group at $\delta 42.0(\mathrm{C}-4)$, and a methyl group at $\delta 26.7$ (Me-44) revealed an $\alpha, \beta$-unsaturated carbonyl functionality connected to the 1,7-diol unit.

A 1,5-diol moiety was assembled using successive TOCSY and COSY correlations from H35 to H39. Due to overlapping signals in the methylene region, an LR-HSQMBC experiment [17] was employed (Figure S6, Supplementary Materials) to confirm the 1,5-diol moiety showing a long-range ${ }^{5} \mathrm{~J}_{\mathrm{CH}}$ heteronuclear coupling from the proton at $\delta 5.09(\mathrm{H}-39)$ to the oxymethine carbon at $\delta 71.1(\mathrm{H}-35)$. $\mathrm{HMBC}$ correlations from $\mathrm{H} 39$ to another quaternary carbon at $\delta 34.6$ as well as to three isochronous methyl groups at $\delta 26.0$ allowed the extension of the structure to include the tert-butyl moiety. Moreover, an HMBC correlation from $\mathrm{H} 39$ to the carbonyl carbon at $\delta 167.1$ (C-1) linked these partial structures via an ester bond.

In parallel to the 2D COSY and TOCSY experiments, a set of 1D-TOCSY experiments, with selective irradiation of H5, H35, and H39 with different mixing times between 20 and 150 ms (Figures S9-S11, Supplementary Materials), were recorded in methanol- $d 4$ and helped assign the spin systems involving each of the individual oxymethines. These spectra also included information concerning the distance between the resonances; as the mixing times lengthened the correlations with more distant protons were observed [18]. Methanol- $d 4$ was used as a solvent because the proton signals for H5 ( $\delta 4.21)$ and H35 (84.21) were separated from the other oxymethine signals ( $83.56-3.54)$ in this solvent. This data set confirmed the locations of the 1,7-diol and 1,5-diol units as shown with bolded bonds in Figure 2.

The substructure shown in Figure 2 accounted for $\mathrm{C}_{31} \mathrm{H}_{64} \mathrm{O}_{6}$, leaving a $\mathrm{C}_{13} \mathrm{H}_{20} \mathrm{O}_{4}$ portion of the molecular formula to be deduced as follows. Three sets of almost identical chemical shifts belonging to chemically equivalent structural units were unassigned at this point: one set of methylene signals $\left(\mathrm{G}_{1}: \delta_{\mathrm{C}} 22.8-22.4, \delta_{\mathrm{H}} 2.15-2.04 / 1.89-1.76\right)$, another set of downfield shifted methylene signals $\left(\mathrm{G}_{2}: \delta_{\mathrm{C}}\right.$ $\left.38.7-38.2, \delta_{\mathrm{H}} 1.82-1.73\right)$, and a set of signals accounting for five oxymethine groups $\left(\mathrm{G}_{3}: \delta_{\mathrm{C}} 71.2-70.8, \delta_{\mathrm{H}}\right.$ 4.00-3.93) (this latter band includes C-31, as pictured in Figure 2, as well as four additional oxymethines). In addition, five of the six protons that accounted for the $\mathrm{OH}$ signal at $\delta_{\mathrm{H}} 5.74$ remained unassigned. HMBC correlations between all three groups of protons as well as COSY correlations between $\mathrm{G}_{1}$ and $G_{2}$, between $G_{2}$ and $G_{3}$, and between $G_{3}$ and the hydroxy signal at $\delta_{H} 5.74$ allowed assignment of another four 1-5-diol groups. In addition, MS/MS fragmentation showed the loss of eight 18 mass unit 
fragments, indicating the presence of a total of eight free hydroxy groups about the macrolide ring. Considering the molecular formula and the remaining NMR data, 1,5-diol relationships were required to connect the partial structure in Figure 2 to a 40 -membered polyhydroxy macrolide, as shown in Figure 1. Unfortunately, the absolute configuration of palstimolide (1) could not be determined due to the small amount isolated and its complex molecular structure.

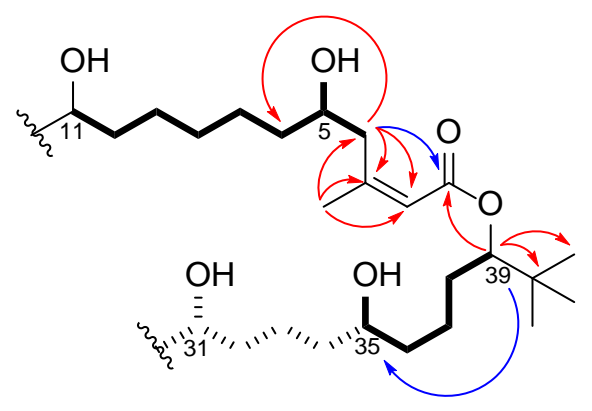

Figure 2. Key correlations deduced from COSY/TOCSY (bolded bonds), HMBC data (red arrows), and LR-HSQMBC data (blue arrows) leading to the partial structure of palstimolide A (1). The dashed bond section was assembled from 1D TOCSY data in $\mathrm{MeOH}-d_{4}$, which connected H35 with H31.

\subsection{Bioactivity Testing}

Palstimolide A (1) showed potent antimalarial activity against the blood stage of the malaria parasite Plasmodium falciparum $\mathrm{Dd} 2\left(\mathrm{IC}_{50}=172.5 \mathrm{nM}\right)$ in combination with a low toxicity to liver HepG2 cells $\left(\mathrm{IC}_{50}=5040 \mathrm{nM}\right)$, resulting in a selectivity index of 29.2. The macrolide also showed activity against the intracellular Leishmania donovani parasite infecting murine macrophage cells $\left(\mathrm{IC}_{50}=4.67\right.$ $\mu \mathrm{M})$ with at least a 2-fold toxicity window (the cytotoxic concentration $50 \%\left(\mathrm{CC}_{50}\right)$ was above the maximum tested concentration of $10 \mu \mathrm{M}$ ) (Table 1). Even though the selectivity towards the host cells was only moderate, it is remarkable that palstimolide A resulted in more than $95 \%$ intracellular elimination at $5 \mu \mathrm{M}$ in vitro. This indicates that the compound was able to eliminate $95 \%$ of the parasites compared to untreated control cells ( $=0 \%$ efficacy) and non-infected controls ( $=100 \%$ efficacy). Parasite reduction is an important measurement to predict the in vivo efficacy of a compound. In the future, we hope to conduct a pharmacokinetic analysis on the compound followed by an in vivo antiparasitic efficacy model using infected mice; however, this requires the availability of additional compound supplies, perhaps through total chemical synthesis. The related metabolite, bastimolide A (2), was previously shown to exhibit a very similar biological profile compared to palstimolide A against several Plasmodium strains $(80-270 \mathrm{nM})$ and mammalian cell lines $(2.1 \mu \mathrm{M}$ against Vero epithelial cells and $3.1 \mu \mathrm{M}$ against the MCF-7 cell line). Thus, the bioactivity of palstimolide A is similar to that of other members of this compound class.

In general, this class of polyhydroxy macrolides shows a broad range of biological activity, such as antimalarial, antiparasitic, antifungal, and chemotactic activity $[6,8-11,19,20]$. The cytotoxic activity of members of this class is moderate-to-weak ( $\mathrm{IC}_{50} \mathrm{~S}$ of 0.87 to around $12 \mu \mathrm{M}$, with amantelide $\mathrm{A}$ being the most cytotoxic; cytotoxic activity for nuiapolide was not reported as a pure compound, however, the crude extract showed no cytotoxic activity at $25 \mu \mathrm{g} / \mathrm{mL}$ ). 
Table 1. NMR spectroscopic data for palstimolide A (1) in pyridine- $d_{5}$.

\begin{tabular}{|c|c|c|c|c|c|}
\hline \# & $\delta_{C}{ }^{a}$ & $\delta_{\mathrm{H}}{ }^{b}$, mult $(J$ in $\mathrm{Hz})$ & HMBC $^{c}$ & $\cos ^{d}$ & TOCSY $^{d}$ \\
\hline 1 & 167.1 & - & & & \\
\hline 2 & 117.8 & $6.01, \mathrm{~s}$ & $1,3,4,5,44$ & $4 \mathrm{a}, \mathrm{Me}-44$ & $4 a, 4 b, 5, M e-44$ \\
\hline 3 & 159.9 & - & & & \\
\hline $4 a$ & 42.0 & $3.38, \mathrm{dd}(12.5,3.9)$ & $2,3,5,6,44$ & $4 b, 5$ & $2,4 \mathrm{~b}, 5,5-\mathrm{OH}, 6 \mathrm{a}, 6 \mathrm{~b}, 7 \mathrm{a}, 7 \mathrm{~b}, 8 \mathrm{a}, 8 \mathrm{~b}$ \\
\hline $4 b$ & & $2.92, \mathrm{dd}(12.4,8.8)$ & $2,3,5,6,44$ & $4 a, 5$ & $2,4 \mathrm{~b}, 5,5-\mathrm{OH}, 6 \mathrm{a}, 6 \mathrm{~b}, 7 \mathrm{a}, 7 \mathrm{~b}, 8 \mathrm{a}, 8 \mathrm{~b}$ \\
\hline 5 & 71.1 & $4.21, \mathrm{~b}$ & 7 & $4 a, 4 b, 6 a, 6 b$ & $4 a, 4 b, 5-O H, 6 a, 6 b, 7 a, 7 b, 8 a, 8 b$ \\
\hline $5-\mathrm{OH}$ & - & $5.82, \mathrm{~b}$ & & 5 & $4 a, 4 b, 5$ \\
\hline $6 a$ & 39.0 & 1.78 & $4,5,7,8$ & 4 & $4 a, 4 b, 5$ \\
\hline $6 \mathrm{~b}$ & & 1.74 & & 4 & $4 a, 4 b, 5$ \\
\hline $7 a$ & 26.4 & 1.80 & $5,6,8$ & & \\
\hline $7 \mathrm{~b}$ & & 1.58 & $5,6,8,9$ & & \\
\hline $8 \mathrm{a}$ & 30.4 & $1.48, \mathrm{~m}$ & $7 / 9,6 / 10$ & $7 \mathrm{a}, 7 \mathrm{~b} / 9 \mathrm{a}, 9 \mathrm{~b}$ & $4 a, 4 b, 5,7 a, 7 b, 9 a, 9 b, 11$ \\
\hline $8 \mathrm{~b}$ & & $1.42, \mathrm{~m}$ & $7 / 9,6 / 10$ & $7 a, 7 b / 9 a, 9 b$ & $4 a, 4 b, 5,7 a, 7 b, 9 a, 9 b, 11$ \\
\hline $9 a$ & 26.5 & 1.74 & 8 & & \\
\hline $9 b$ & & 1.58 & $7,8,10,11$ & & \\
\hline 10 & 38.4 & 1.69 & $8,11, \mathrm{G} 2$ & & \\
\hline 11 & 71.1 & 3.87 & $9,10, \mathrm{G} 2$ & $10, \mathrm{G} 2$ & $5,8 \mathrm{a}, 8 \mathrm{~b}, \mathrm{G} 1 \mathrm{a}, \mathrm{G} 1 \mathrm{~b}, \mathrm{G} 2, \mathrm{G} 3$ \\
\hline $11-\mathrm{OH}$ & - & $5.66, \mathrm{~b}$ & & 11 & 11 \\
\hline 12 & G2 & G2 & G1, G3 & G1a, G1b, G3 & G1a, G1b, G3 \\
\hline $13 a$ & G1 & G1a & G2, G3 & G2 & G2, G3 \\
\hline $13 \mathrm{~b}$ & & G1b & G2, G3 & (G2) & \\
\hline 14 & G2 & G2 & G1, G3 & G1a, G1b, G3 & G1a, G1b, G3 \\
\hline 15 & G3 & G3 & G1, G2 & G2 & G1a, G1b, G2, G4 \\
\hline $15-\mathrm{OH}$ & - & 5.74 & & G3 & \\
\hline 16 & G2 & G2 & G1, G3 & G1a, G1b, G3 & G1a, G1b, G3 \\
\hline $17 a$ & G1 & G1a & G2, G3 & G2 & G2, G3 \\
\hline $17 \mathrm{~b}$ & & G1b & G2, G3 & (G2) & \\
\hline 18 & G2 & G2 & G1, G3 & G1a, G1b, G3 & G1a, G1b, G3 \\
\hline 19 & G3 & G3 & G1, G2 & G2 & G1a, G1b, G2, G4 \\
\hline $19-\mathrm{OH}$ & - & 5.74 & & G3 & \\
\hline 20 & G2 & G2 & G1, G3 & G1a, G1b, G3 & G1a, G1b, G3 \\
\hline $21 \mathrm{a}$ & G1 & G1a & G2, G3 & G2 & G2, G3 \\
\hline $21 \mathrm{~b}$ & & G1b & $\mathrm{G} 2, \mathrm{G} 3$ & (G2) & \\
\hline 22 & G2 & G2 & G1, G3 & G1a, G1b, G3 & G1a, G1b, G3 \\
\hline 23 & G3 & G3 & G1, G2 & G2 & G1a, G1b, G2, G4 \\
\hline $23-\mathrm{OH}$ & - & 5.74 & & G3 & \\
\hline 24 & G2 & G2 & G1, G3 & G1a, G1b, G3 & G1a, G1b, G3 \\
\hline $25 a$ & G1 & G1a & G2, G3 & G2 & G2, G3 \\
\hline $25 \mathrm{~b}$ & & G1b & G2, G3 & (G2) & \\
\hline 26 & G2 & G2 & G1, G3 & G1a, G1b, G3 & G1a, G1b, G3 \\
\hline 27 & G3 & G3 & G1, G2 & G2 & G1a, G1b, G2, G4 \\
\hline $27-\mathrm{OH}$ & - & 5.74 & & G3 & \\
\hline 28 & G2 & G2 & G1, G3 & G1a, G1b, G3 & G1a, G1b, G3 \\
\hline $29 a$ & G1 & G1a & G2, G3 & G2 & G2, G3 \\
\hline $29 \mathrm{~b}$ & & G1b & $\mathrm{G} 2, \mathrm{G} 3$ & (G2) & \\
\hline 30 & G2 & G2 & G1, G3 & G1a, G1b, G3 & G1a, G1b, G3 \\
\hline 31 & G3 & G3 & G1, G2 & G2 & G1a, G1b, G2, G4 \\
\hline $31-\mathrm{OH}$ & - & 5.74 & & G3 & \\
\hline 32 & G2 & G2 & G1, G3 & G1a, G1b, G3 & G1a, G1b, G3 \\
\hline $33 a$ & G1 & G1a & G2, G3 & G2 & G2, G3 \\
\hline $33 \mathrm{~b}$ & & G1b & G2, G3 & (G2) & \\
\hline 34 & G2 & G2 & G1, G3 & G1a, G1b, G3 & G1a, G1b, G3 \\
\hline 35 & 71.1 & 3.87 & $37, \mathrm{G} 1, \mathrm{G} 2$ & $36, \mathrm{G} 2$ & $35-\mathrm{OH}, 37 \mathrm{a}, 39, \mathrm{G} 1, \mathrm{G} 2, \mathrm{G} 3$ \\
\hline $35-\mathrm{OH}$ & - & 5.78 & & 35 & \\
\hline 36 & 38.2 & 1.78 & $35,37,38, \mathrm{G} 1, \mathrm{G} 2$ & & $37 a$ \\
\hline $37 a$ & 23.5 & 1.92 & 38,39 & & $35,37 b, 38 a, 39$ \\
\hline $37 \mathrm{~b}$ & & 1.60 & 38,39 & & \\
\hline $38 \mathrm{a}$ & 30.2 & 1.70 & 37 & 39 & $35,39,37 a$ \\
\hline $38 \mathrm{~b}$ & & 1.64 & $37,39,40$ & 39 & $35,39,37 a$ \\
\hline 39 & 79.6 & $5.09, \mathrm{dd}(10.3,1.7)$ & $1,37,38,40,41-43$ & $38 \mathrm{a}, 38 \mathrm{~b}$ & $35,35-\mathrm{-OH}, 37 \mathrm{a}, 37 \mathrm{~b}, 38 \mathrm{a}, 38 \mathrm{~b}$ \\
\hline 40 & 34.6 & - & & & \\
\hline Me-41 & 26.0 & $0.94, \mathrm{~s}$ & 39,40 & & \\
\hline $\mathrm{Me}-42$ & 26.0 & $0.94, \mathrm{~s}$ & 39,40 & & \\
\hline Me-43 & 26.0 & $0.94, \mathrm{~s}$ & 39,40 & & \\
\hline Me-44 & 26.7 & $2.09, \mathrm{~s}$ & $2,3,4$ & 2 & 2 \\
\hline
\end{tabular}




\section{Materials and Methods}

\subsection{Chemistry}

\subsubsection{General Experimental Procedures}

Optical rotations were measured on a JASCO P-2000 polarimeter (JASCO Corporation, Tokyo, Japan), UV/Vis data were obtained using a Beckman DU800 spectrophotometer (Beckman Coulter, Brea, CA, USA), and IR spectra were recorded on a Nicolet 100 FT-IR spectrometer (Nicolet, Madison, WI, USA). NMR data were obtained on a Bruker AVANCE III $600 \mathrm{MHz}$ NMR with a $1.7 \mathrm{~mm}$ dual tune TCI cryoprobe (Bruker, Billerica, MA, USA) and the 1D TOCSY experiments were performed on a JEOL ECZ 500 NMR spectrometer equipped with a $3 \mathrm{~mm}$ inverse probe (H3X) (JEOL Ltd., Tokyo, Japan). Data were recorded in either pyridine- $d 5$ or methanol- $d 4$ and adjusted to the residual solvent peak (pyridine- $d 5 \delta_{\mathrm{H}} 7.22, \delta_{\mathrm{C}}$ 123.87; methanol- $d 4 \delta_{\mathrm{H}} 3.31, \delta_{\mathrm{C}} 49.00$ ). Deuterated NMR solvents were purchased from Cambridge Isotope Laboratories (Tewksbury, MA, USA). For high resolution electrospray mass spectrometric analysis (HR-ESI-MS), an Agilent 6530 Accurate Mass QTOF mass spectrometer was used in the positive ion mode (Agilent, Santa Clara, CA, USA). Semi-preparative HPLC was performed on a Thermo Fisher Scientific HPLC system with a Thermo Dionex UltiMate 3000 pump, RS autosampler, RS diode array detector, and automated fraction collector (Thermo Fisher Scientific, Waltham, MA, USA). All solvents were HPLC grade except for water, which was purified by a Millipore Milli-Q system before use.

\subsubsection{Extraction and Isolation}

A $1 \mathrm{~L}$ packed volume of a colorless cyanobacterial collection (voucher specimen available from W.H.G. as collection number RT13 CARTER 10/4) was collected from Palmyra Atoll in the Central Pacific Ocean. Samples were stored in $70 \% \mathrm{EtOH}$ at $-20{ }^{\circ} \mathrm{C}$ prior to extraction. Approximately $90 \mathrm{~g}$ (dry wt) of cyanobacterial mat was extracted repeatedly with $\mathrm{CH}_{2} \mathrm{Cl}_{2} / \mathrm{MeOH}(2: 1)$ to afford $0.3 \mathrm{~g}$ of crude extract (labeled as extract 2238). The material was fractionated by vacuum liquid chromatography (VLC), consisting of TLC-grade (H) silica (Sigma-Aldrich, St. Louis, MO, USA), using a stepwise gradient of increasing polarity, starting with 10\% EtOAc in hexanes and finishing with $100 \% \mathrm{MeOH}$, to produce nine fractions (B-J). Fractions 2238-H and 2238-I (2238-H eluted with 25\% methanol in EtOAc $(60.5 \mathrm{mg}), 2238-\mathrm{I}$ eluted with $100 \%$ methanol $(146.7 \mathrm{mg}))$ were subjected to fractionation via solid phase extraction using a $1.0 \mathrm{~g}$ SPE Bond Elut C18 cartridge (Agilent, Santa Clara, CA, USA) with $35 \%$ to $100 \% \mathrm{ACN}$ in $\mathrm{H}_{2} \mathrm{O}$ resulting in five fractions each (H1-H5 and I1-I5). Fractions 2238-H2 and 2238-I2 (eluted with 50\% ACN, $2.47 \mathrm{mg}$ and $3.46 \mathrm{mg}$, respectively) were pooled and subjected to semi-preparative HPLC purification using a linear gradient on a Synergi $5 \mu \mathrm{m}$ Fusion-RP $250 \times 10.0 \mathrm{~mm}$ column (Phenomenex, Torrance, CA, USA) from (A) $\mathrm{H}_{2} \mathrm{O}+0.1 \%$ formic acid to (B) ACN $+0.1 \%$ formic acid at a flow rate of $5 \mathrm{~mL} / \mathrm{min}$, monitored at $220 \mathrm{~nm}$. The gradient started with $30 \% \mathrm{~B}$, followed by an increase to $62.5 \% \mathrm{~B}$ in $15 \mathrm{~min}$, and yielded $0.7 \mathrm{mg}$ of compound 1 (RT = $12.5 \mathrm{~min}$ ).

Palstimolide A (1). White, amorphous solid; $[\alpha]^{25} \mathrm{D} 13.3$ (c 0.3, MeOH); UV (MeOH) $\lambda_{\max } 213 \mathrm{~nm}$ (log $\varepsilon$ 3.46), 243 nm (log ع 3.26); IR (KBr) 3393, 2922, 2852, 1579, 1455, 1366, 1249, 1177,1119, $1025 \mathrm{~cm}^{-1}$; ${ }^{1} \mathrm{H}$-and ${ }^{13} \mathrm{C}-\mathrm{NMR}$, see Table 2; HR-ESI-MS $[\mathrm{M}+\mathrm{H}]^{+} \mathrm{m} / \mathrm{z} 773.6182$ (calcd for $\mathrm{C}_{44} \mathrm{H}_{85} \mathrm{O}_{10}{ }^{+}$, 773.6137).

Table 2. Bioactivity of palstimolide A and bastimolide A (literature data [6]).

\begin{tabular}{ccc}
\hline Bioactivity Assay & $\begin{array}{c}\text { Palstimolide A } \\
\text { (95\% Confidence Interval) }\end{array}$ & Bastimolide A \\
\hline P. falciparum & $172.5 \mathrm{nM}(138.5-214.2 \mathrm{nM})$ & $80-270 \mathrm{nM}$ \\
L. donovani & $4670 \mathrm{nM}(3067-6273 \mathrm{nM})$ & $3000 \mathrm{nM}$ \\
HepG2 human liver cell line & $5040 \mathrm{nM}(4410-5754 \mathrm{nM})$ & n.d. \\
B10R murine macrophages & $>10,000 \mathrm{nM}$ & n.d. \\
(L. donovani host cell toxicity) & n.d. & $2100 \mathrm{nM}$ \\
Vero epithelial cells &
\end{tabular}




\subsection{Anti-Leishmanial Testing}

\subsubsection{Anti-Leishmania Assay}

Leishmania donovani (MHOM/ET/67/HU3) promastigotes were maintained at $28{ }^{\circ} \mathrm{C}$ in $\mathrm{M} 199$ medium (Gibco, Gaithersburg, MD, USA), supplemented with 10\% heat-inactivated fetal bovine serum (FBS, Sigma-Aldrich, St. Louis, MO, USA), 25 mM HEPES, at pH 7.2, and sub-cultured every 4 or 5 days. At 5 days after sub-culture, the parasites were counted and used to infect B10R (murine monocyte cell line), cultivated in DMEM (Gibco, Gaithersburg, MD, USA) supplemented with 10\% FBS (Gibco, Gaithersburg, MD, USA) at $37^{\circ} \mathrm{C}$ with $5 \% \mathrm{CO}_{2}$. For the infection, 10,000 cells were mixed with $2 \times 10^{5}$ parasites per well in a 384-well plate in a total volume of $50 \mu \mathrm{l}$. For every plate, 16 wells were untreated (negative control) and 16 wells were uninfected (positive control phenotype). Amphotericin B (Sigma-Aldrich \#A2942, St. Louis, MO, USA) was used as a reference positive control. Compounds were transferred to plates using an acoustic transfer system (ATS, EDC Biosystems, Fremont, CA, USA) from a stock plate. Compounds were diluted in DMSO and tested at 10 concentrations using a 2-fold serial dilution starting at $10 \mu \mathrm{M}$. The maximum DMSO concentration in the assay was $0.1 \%$ DMSO. After incubating the plates at $37^{\circ} \mathrm{C}, 5 \% \mathrm{CO}_{2}$ for $72 \mathrm{~h}$, the wells were fixed by adding paraformaldehyde for a minimum of $30 \mathrm{~min}$ at a final concentration of $2 \%$. After being fixed, the content of the wells was stained with 4',6-diamidino-2-phenylindole (DAPI, Sigma-Aldrich \#10236276001, St. Louis, MO, USA) at $5 \mu \mathrm{g} / \mathrm{mL}$ final concentration. The plate was read using an ImageXpress MicroXL automated microscope (Molecular Devices, San Jose, CA, USA) and 4 images per well were acquired. A custom software was developed for the image analysis to quantify the number of host cells and parasites per well based on size, shape, and intensity of the staining. The antiparasitic activity was calculated based on the relative parasite reduction compared to untreated controls (normalized average $=0 \%$ activity) and uninfected wells (normalized average $=100 \%$ activity). To calculate the $\mathrm{IC}_{50}$ values, GraphPad Prism 6 was used applying a dose-response inhibition nonlinear regression curve fit with variable slope (four parameters). The assay was performed in biological duplicate and the results are presented as an average of the replicates.

\subsubsection{Host Cell Toxicity}

The host cell toxicity was assessed as part of the anti-Leishmanial testing. The average number of host cells in the untreated control wells were counted ( $=100 \%$ viability of the host cells). For every tested well, the percentage of live cells relative to the average of the untreated controls was calculated. Cells were stained and counted according to the procedures described in paragraph 3.2.1. The assay was performed in biological duplicate and the results are presented as an average of the replicates.

\subsection{Anti-Malarial Testing}

\subsubsection{Anti-Plasmodium Assay}

Asexual blood stage Plasmodium falciparum Dd2 strain parasites were cultured using standard conditions [21], using RPMI media (Life Technologies, Carlsbad, CA, USA) supplemented with $0.014 \mathrm{mg} / \mathrm{mL}$ hypoxanthine (Sigma-Aldrich; prepared fresh), $0.05 \mathrm{mg} / \mathrm{mL}$ gentamycin, $38.4 \mathrm{mM}$ HEPES (Sigma-Aldrich), 0.2\% sodium bicarbonate (Sigma-Aldrich), $3.4 \mathrm{mM}$ sodium hydroxide (Sigma-Aldrich), $0.05 \% \mathrm{O}+$ human serum (Denatured at $56{ }^{\circ} \mathrm{C}$ for $40 \mathrm{~min}$; Interstate Blood Bank, Memphis, TN, USA), and $0.0025 \%$ albumax (Thermo Fisher Scientific, Waltham, MA, USA). Human O+ whole blood was obtained from the Scripps Research Institute (TSRI) blood bank. Leukocyte-filtered erythrocytes were stored at 50\% hematocrit in media as above except without $\mathrm{O}+$ human serum and with $2 \mathrm{x}$ albumax concentration at $4{ }^{\circ} \mathrm{C}$. Cultures were monitored every one to two days via Giemsa-stained thin blood smears of parasite infected erythrocytes. Compound potency against asexual blood stage parasites was determined using a SYBR Green I-based fluorescence assay [22]. Asynchronous P. falciparum parasites (Dd2 strain) were cultured in standard conditions prior to being assayed. Parasites were 
initially cultured at $0.6 \%$ parasitemia and each compound was tested for anti-parasite potency after $72 \mathrm{~h}$ at $37^{\circ} \mathrm{C}$. Compounds were dissolved in DMSO and diluted 1000-fold in the assay resulting in a maximum final DMSO concentration of $0.1 \%$ DMSO. Assays were conducted in technical duplicates with three independent biological replicates on a 12-point concentration curve prepared by three-fold dilution from $6.7 \mu \mathrm{M}$ to $0.11 \mathrm{nM}$. Artemisinin and chloroquine were simultaneously used as positive controls. $\mathrm{IC}_{50}$ values were obtained using normalized SYBR Green I fluorescence intensity, with $6.7 \mu \mathrm{M}$ artemisinin defined as zero parasite survival, and analyzed via non-linear variable slope four-parameter regression curve-fitting model in Prism 6 (GraphPad Software Inc).

\subsubsection{HepG2 Toxicity}

The HepG2 toxicity assays were performed as previously reported [23]. Briefly, HepG2-A16-CD81EGFP were cultured at $37{ }^{\circ} \mathrm{C}$ in $5 \% \mathrm{CO}_{2}$ in DMEM (Life Technologies) supplemented with $10 \%$ FBS, $0.29 \mathrm{mg} / \mathrm{mL}$ glutamine, 100 units $/ \mathrm{mL}$ of penicillin, and $100 \mu \mathrm{g} / \mathrm{mL}$ streptomycin. A total of $3 \times 10^{3}$ HepG2-A16-CD81EGFP cells in $10 \mu \mathrm{L}$ of culture medium (DMEM without Phenol Red (Life Technologies), 5\% FBS, and 5x Pen Strep Glutamine (Life Technologies)) were seeded in 1536-well plates $24 \mathrm{~h}$ prior to treatment. A $50 \mathrm{~nL}$ sample of compound was transferred via acoustic transfer system (ATS) (Biosera, Kansas City, MO, USA) into the assay plates and compounds were tested in technical duplicates on a 12-point concentration curve prepared by three-fold dilution from $10.0 \mu \mathrm{M}$ to $0.15 \mathrm{nM}$. Compounds were dissolved in DMSO using a maximum DMSO concentration of $0.1 \%$ in the assay. Puromycin was used as a positive control for HepG2 cytotoxicity. After 48 h, HepG2-A16-CD81EGFP cell viability was quantified by bioluminescence measurement Envision Multilabel Reader (PerkinElmer, Waltham, MA, USA) using Cell titer Glo (Promega, Madison, WI, USA). IC 50 values were obtained using the normalized bioluminescence intensity and a non-linear variable slope four-parameter regression curve-fitting model in Prism 6 (GraphPad Software Inc, San Diego, CA, USA).

\section{Conclusions}

In summary, we reported herein the isolation and planar structure elucidation of palstimolide A (1), a structurally complex polyhydroxy macrolide. The compound is characterized by a 40-membered macrolactone ring, nine hydroxy group equivalents that form seven 1,5-diol and one 1,7-diol relationships around the ring, a tert-butyl moiety, and an $\alpha, \beta$-unsaturated carbonyl moiety. Extensive NMR experiments allowed the elucidation of the planar structure despite the small amount isolated $(0.7 \mathrm{mg}, 0.9 \mu \mathrm{mol})$. Palstimolide A shows potent antimalarial activity together with promising preliminary results as an anti-leishmanial agent. This new natural product belongs to a small group of related polyhydroxy macrolides. Members of this natural product class have been isolated from marine Cyanobacteria collected at different tropical regions around the world (e.g., Guam, Hawaii, Panama (Caribbean), and Palmyra Atoll). Likely, these elaborate structures provide an evolutionary advantage for producing cyanobacterial strains; however, this requires further investigation. This structural class appears to be highly attractive for drug discovery efforts because most of these metabolites show a range of biological activities, especially to intracellular parasites.

Supplementary Materials: The following are available online: Figure S1: 1H-NMR spectrum of palstimolide A (1) in pyridine-d5, $600 \mathrm{MHz}$, Figure S2: HSQC spectrum of palstimolide A (1) in pyridine-d5, $600 \mathrm{MHz}$, Figure S3: Extended 1H-NMR spectrum of palstimolide A (1) in pyridine-d5, $600 \mathrm{MHz}$, Figure S4: Extended 1H-NMR spectrum of palstimolide A (1) in pyridine-d5, $600 \mathrm{MHz}$, Figure S5: HMBC spectrum of palstimolide A (1) in pyridine-d5, $600 \mathrm{MHz}$, Figure S6: LR-HSQMBC spectrum of palstimolide A (1) in pyridine-d5, $600 \mathrm{MHz}$. Figure S7: COSY spectrum of palstimolide A (1) in pyridine-d5, $600 \mathrm{MHz}$, Figure S8: TOCSY spectrum of palstimolide A (1) in pyridine-d5, $600 \mathrm{MHz}$, Figure S9: 1D TOCSY spectrum of palstimolide A (1) in methanol-d4 (500 MHz) with selective irradiation of $\mathrm{H} 5$ at 3.78 ppm, Figure S10: 1D TOCSY spectrum of palstimolide A (1) in methanol-d4 (500 $\mathrm{MHz}$ ) with selective irradiation of $\mathrm{H} 35$ at $3.45 \mathrm{ppm}$, Figure S11: 1D TOCSY spectrum of palstimolide A (1) in methanol-d4 (500 MHz) with selective irradiation of $\mathrm{H} 39$ at $4.76 \mathrm{ppm}$.

Author Contributions: Conceptualization: L.K. and W.H.G.; methodology (isolation and structure elucidation): L.K.; methodology (anti-leishmanial testing): J.L.S.-N. and J.M.S.; methodology (anti-malarial testing): K.E. and G.M.L.; methodology (sample collection): J.E.S.; writing—original draft preparation: L.K. and W.H.G.; 
writing-review and editing, L.K., J.L.S.-N., G.M.L., and W.H.G.; all authors have read and agreed to the published version of the manuscript. All authors have read and agreed to the published version of the manuscript.

Funding: This research was funded by NIH grant GM107550 (W.H.G.). L.K. was supported by the Deutsche Forschungsgemeinschaft (Grant KE 2172/3-1 and KE 2172/4-1).

Acknowledgments: We thank the US Department of Fish and Wildlife for permission to make collections of Cyanobacteria from Palmyra Atoll. We thank B. Duggan for assistance with NMR experiments.

Conflicts of Interest: The authors declare no conflict of interest.

\section{References}

1. Burja, A.M.; Banaigs, B.; Abou-Mansour, E.; Grant Burgess, J.; Wright, P.C. Marine cyanobacteria-A prolific source of natural products. Tetrahedron 2001, 57, 9347-9377. [CrossRef]

2. Tan, L.T. Filamentous tropical marine cyanobacteria: A rich source of natural products for anticancer drug discovery. J. Appl. Phycol. 2010, 22, 659-676. [CrossRef]

3. Niedermeyer, T. Anti-infective Natural Products from Cyanobacteria. Planta Med. 2015, 81, 1309-1325. [CrossRef] [PubMed]

4. Karpiński, T.M. Marine Macrolides with Antibacterial and/or Antifungal Activity. Mar. Drugs 2019, $17,241$. [CrossRef]

5. Wang, M.; Zhang, J.; He, S.; Yan, X. A Review Study on Macrolides Isolated from Cyanobacteria. Mar. Drugs 2017, 15, 126. [CrossRef]

6. Shao, C.-L.; Linington, R.G.; Balunas, M.J.; Centeno, A.; Boudreau, P.; Zhang, C.; Engene, N.; Spadafora, C.; Mutka, T.S.; Kyle, D.E.; et al. Bastimolide A, a Potent Antimalarial Polyhydroxy Macrolide from the Marine Cyanobacterium Okeania hirsuta. J. Org. Chem. 2015, 80, 7849-7855. [CrossRef]

7. Shao, C.-L.; Mou, X.-F.; Cao, F.; Spadafora, C.; Glukhov, E.; Gerwick, L.; Wang, C.-Y.; Gerwick, W.H. Bastimolide B, an Antimalarial 24-Membered Marine Macrolide Possessing a tert-Butyl Group. J. Nat. Prod. 2018, 81, 211-215. [CrossRef]

8. Salvador-Reyes, L.A.; Sneed, J.; Paul, V.J.; Luesch, H. Amantelides A and B, Polyhydroxylated Macrolides with Differential Broad-Spectrum Cytotoxicity from a Guamanian Marine Cyanobacterium. J. Nat. Prod. 2015, 78, 1957-1962. [CrossRef]

9. Mori, S.; Williams, H.; Cagle, D.; Karanovich, K.; Horgen, F.; III, R.; Watanabe, C. Macrolactone Nuiapolide, Isolated from a Hawaiian Marine Cyanobacterium, Exhibits Anti-Chemotactic Activity. Mar. Drugs 2015, 13, 6274-6290. [CrossRef]

10. MacMillan, J.B.; Molinski, T.F. Caylobolide A, a Unique 36-Membered Macrolactone from a Bahamian Lyngbya majuscula. Org. Lett. 2002, 4, 1535-1538. [CrossRef]

11. Salvador, L.A.; Paul, V.J.; Luesch, H. Caylobolide B, a macrolactone from symplostatin 1-producing marine cyanobacteria Phormidium spp. from Florida. J. Nat. Prod. 2010, 73, 1606-1609. [CrossRef] [PubMed]

12. Andrianasolo, E.H.; Gross, H.; Goeger, D.; Musafija-Girt, M.; McPhail, K.; Leal, R.M.; Mooberry, S.L.; Gerwick, W.H. Isolation of swinholide A and related glycosylated derivatives from two field collections of marine cyanobacteria. Org. Lett. 2005, 7, 1375-1378. [CrossRef] [PubMed]

13. Williamson, R.T.; Boulanger, A.; Vulpanovici, A.; Roberts, M.A.; Gerwick, W.H. Structure and absolute stereochemistry of phormidolide, a new toxic metabolite from the marine cyanobacterium Phormidium sp. J. Org. Chem. 2002, 67, 7927-7936. [CrossRef] [PubMed]

14. Pereira, A.R.; McCue, C.F.; Gerwick, W.H. Cyanolide A, a glycosidic macrolide with potent Molluscicidal activity from the Papua New Guinea cyanobacterium Lyngbya bouillonii. J. Nat. Prod. 2010, 73, 217-220. [CrossRef] [PubMed]

15. Pereira, A.R.; Cao, Z.; Engene, N.; Soria-Mercado, I.E.; Murray, T.F.; Gerwick, W.H. Palmyrolide A, an unusually stabilized neuroactive macrolide from Palmyra Atoll cyanobacteria. Org. Lett. 2010, 12, 4490-4493. [CrossRef] [PubMed]

16. Wang, M.; Carver, J.J.; Phelan, V.V.; Sanchez, L.M.; Garg, N.; Peng, Y.; Nguyen, D.D.; Watrous, J.; Kapono, C.A.; Luzzatto-Knaan, T.; et al. Sharing and community curation of mass spectrometry data with Global Natural Products Social Molecular Networking. Nat. Biotechnol. 2016, 34, 828-837. [CrossRef]

17. Williamson, R.T.; Buevich, A.V.; Martin, G.E.; Parella, T. LR-HSQMBC: A sensitive NMR technique to probe very long-range heteronuclear coupling pathways. J. Org. Chem. 2014, 79, 3887-3894. [CrossRef] 
18. Bax, A.; Davis, D.G. MLEV-17-based two-dimensional homonuclear magnetization transfer spectroscopy. J. Magn. Reson. 1985, 65, 355-360. [CrossRef]

19. Taori, K.; Matthew, S.; Rocca, J.R.; Paul, V.J.; Luesch, H. Lyngbyastatins 5-7, potent elastase inhibitors from Floridian marine cyanobacteria, Lyngbya spp. J. Nat. Prod. 2007, 70, 1593-1600. [CrossRef]

20. Salvador, L.A.; Taori, K.; Biggs, J.S.; Jakoncic, J.; Ostrov, D.A.; Paul, V.J.; Luesch, H. Potent elastase inhibitors from cyanobacteria: Structural basis and mechanisms mediating cytoprotective and anti-inflammatory effects in bronchial epithelial cells. J. Med. Chem. 2013, 56, 1276-1290. [CrossRef]

21. Trager, W.; Jensen, J.B. Human malaria parasites in continuous culture. 1976. J. Parasitol. 2005, 91, 484-486. [CrossRef]

22. Smilkstein, M.; Sriwilaijaroen, N.; Kelly, J.X.; Wilairat, P.; Riscoe, M. Simple and inexpensive fluorescence-based technique for high-throughput antimalarial drug screening. Antimicrob. Agents Chemother. 2004, 48, 1803-1806. [CrossRef] [PubMed]

23. Swann, J.; Corey, V.; Scherer, C.A.; Kato, N.; Comer, E.; Maetani, M.; Antonova-Koch, Y.; Reimer, C.; Gagaring, K.; Ibanez, M.; et al. High-Throughput Luciferase-Based Assay for the Discovery of Therapeutics That Prevent Malaria. ACS Infect. Dis. 2016, 2, 281-293. [CrossRef] [PubMed]

Sample Availability: Samples of the compounds are not available from the authors. 